MATEC Web of Conferences 3, 01067 (2013)

DOI: $10.1051 /$ matecconf/20130301067

(C) Owned by the authors, published by EDP Sciences, 2013

\title{
Thermal analysis of microcrystalline cellulose prepared from esparto grass
}

\author{
D. Trache ${ }^{1}$, K. Khimeche ${ }^{1}$, A. Donnot ${ }^{2}$, and R. Benelmir ${ }^{2}$ \\ ${ }^{1}$ Chimie appliquée, Ecole Militaire Polytechnique E.M.P., B.P 17 Bordj-El-Bahri, Alger, Algérie \\ ${ }^{2}$ LERMAB, Faculté des Sciences et Techniques, Université de Lorraine, 54506 Vandœuvre-les-Nancy, France
}

\begin{abstract}
Alfa fibres are extracted from the plant Stippa tenacissima, or esparto grass (alfa is the Arab name for esparto), and grows in the dry regions of North Africa. It belongs to the graminacies family and grows to a height of about $1 \mathrm{~m}$. These fibres are mostly used in the production of paper. Recently, they have been used as reinforcement in the production of biodegradable composites.

The aim of the present work was to prepare microcrystalline cellulose from esparto grass using the hydrolysis process. The products obtained are characterized with thermogravimetric analysis.

As a result, the thermal decomposing patterns of the cellulosic preparations, obtained by hydrochloric hydrolysis gave additional evidence to the relatively higher stability of the more crystalline cellulosic preparations. In the main decomposition stage, the cleavage of the glycosidic linkages of cellulose reduces the polymerization degree leading to the formation of $\mathrm{CO}_{2}, \mathrm{H}_{2} \mathrm{O}$ and other hydrocarbon derivatives.
\end{abstract}

\section{Introduction}

Esparto grass (Stipa tenacissima L.) occupies in North Africa about 7 million ha. In Algeria, this species grows mainly on the high plateaus in mixture with the sparte (spartum legium). It is in the western south steppes of the country that one meets the vast and greatest esparto expanses (1.2 million hectares in the Saida region) [1-3]. Moreover, cellulose, the most abundant organic compound and a renewable resource, gains increasing importance as raw materials for fuels, chemicals, paper industry, building board, and food industries because of its low cost, wide availability, and low content in nonfibrous materials. Microcrystalline cellulose has been used for many years in different industries like cosmetics, plastics, food, pharmaceuticals, etc. MCC is obtained in industrial scale from wood and cotton cellulose using dilute mineral acids [4].

In the present work, the microcrystalline cellulose was prepared from esparto grass (CMCAlfa) and compared with the commercial microcrystalline cellulose (CMCcom). The Thermal degradation of different samples was done using TGA analysis.

\section{Experimental}

Esparto grass fibres were collected from the Saïda area, in Algeria. The extraction of cellulose from esparto grass (CAlfa) was occurred using the method given elsewhere [5]. Microcrystalline cellulose was prepared using cellulose sample obtained from esparto grass by hydrochloric acid hydrolysis [6].

\section{Results and discussion}

All samples (CAlfa, CMCAlfa and CMCcom) were subjected to TGA analysis under nitrogen atmosphere and a heating rate of $10{ }^{\circ} \mathrm{C} / \mathrm{min}$, occurred from room temperature up to $800{ }^{\circ} \mathrm{C}$. The loss in weight of the MCC particles with the rise in temperature is shown in Figure 1. It was observed that the residue left after degradation was $74.84 \%$ for CAlfa, $88.41 \%$ for CMCAlfa and $92.59 \%$ for CMCcom. The thermal stability for the celluloses followed the order CAlfa $\left(\mathrm{T}_{\text {onset }}=272.04{ }^{\circ} \mathrm{C}\right)<$ CMCAlfa $\left(\mathrm{T}_{\text {onset }}=305.59{ }^{\circ} \mathrm{C}\right)<\mathrm{CMCcom}\left(\mathrm{T}_{\text {onset }}=311.70\right.$ $\left.{ }^{\circ} \mathrm{C}\right)$. CMCcom had a higher thermal stability than CMCAlfa and CAlfa. The highest thermal stability on CMCcom and CMCAlfa can be attributed to their higher flexibility, hence higher possibility of entanglements of the microfibrils. Similar increase in thermal stability caused ascribed to tangling effect of flexible microfirils has been reported in the literature [7]. However, the lower stability observed for CAlfa may be due to the presence of impurities such as hemicelluloses and lignin. 


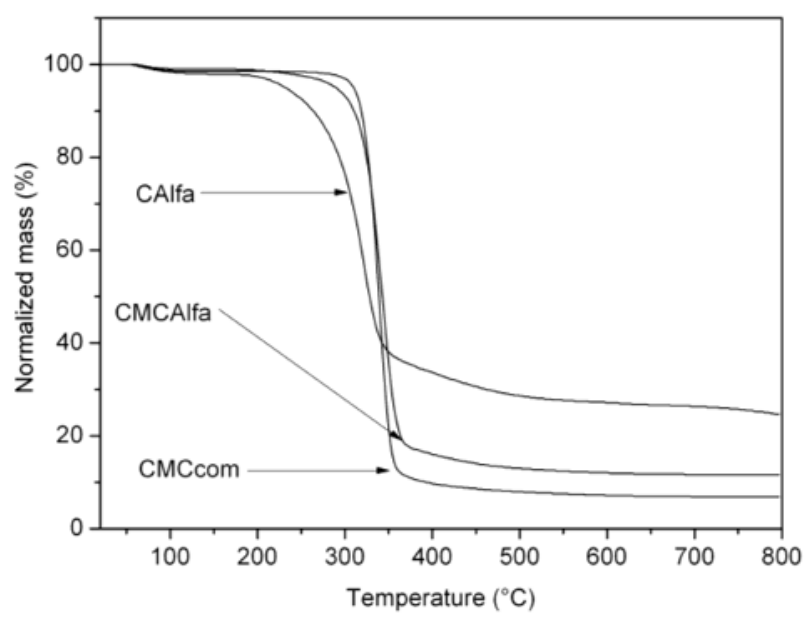

Figure 1. FTIR spectra of alfa grass fibres and cellulose microcrystalline derived from it.

\section{References}

1. A. Bessadok, S. Marais, F. Gouanve, L. Colasse, I. Zimmerlin, S. Roudesli, M. Metayer, Compo. Sci. Technol. 67685 (2007)

2. P. García-Fayos, M.Gasque, Acta Oecol. 30276 (2006)

3. H. Nadji, P.N. Diouf, A. Benaboura, Y. Bedard, B. Riedl, T. Stevanovic, Bioresour. Technol. 1003585 (2009)

4. A.M. Adel, H.Z. Abd El-Wahab, A.A. Ibrahim, M.T. Al-Shemy, Bioresour. Technol. 1014446 (2010)

5. E.M. Maafi, F. Malek, L. Tighzert, P. Dony, J. polym. environ. 18638 (2010)

6. M. Hanna, G. Blby, V. Miladinove, US Patent 6,228,213 (2001)

7. M.A.S.A. Samir, F. Alloin, M. Paillet, A. Dufresne, Macromol. 374313 (2004) 